\title{
EFFECT OF ENVIRONMENTAL PHTHALATE EXPOSURE ON PREGNANCY DURATION AND BIRTH OUTCOMES
}

\section{KINGA POLAŃSKA ${ }^{1}$, DANUTA LIGOCKA ${ }^{2}$, WOJCIECH SOBALA ${ }^{1}$, and WOJCIECH HANKE ${ }^{1}$}

\author{
Nofer Institute of Occupational Medicine, Łódź, Poland \\ ${ }^{1}$ Department of Environmental Epidemiology \\ ${ }^{2}$ Bureau of Quality Assurance
}

\begin{abstract}
Objectives: The objective of this study was to evaluate the impact of phthalate exposure on pregnancy duration and birth outcomes based on the Polish Mother and Child Cohort (REPRO_PL). Material and Methods: Phthalate exposure was determined by measuring 11 phthalate metabolites (mono-ethyl phthalate (MEP), mono-iso-butyl phthalate (MiBP), mono-n-butyl phthalate (MnBP), 3OH-mono-n-butyl phthalate (OH-MnBP), mono-benzyl phthalate (MBzP), mono(2-ethylhexyl) phthalate (MEHP), mono-(2-ethyl-5-hydroxyhexyl) phthalate (MEHHP), mono-(2-ethyl-5-oxohexyl) phthalate (MEOHP), mono-hydroxy-iso-nonyl phthalate (MHiNP), mono-oxo-iso-nonyl phthalate (MOiNP), and mono-n-octyl phthalate (MOP)) in the urine collected from 165 mothers during the third trimester of pregnancy by high performance liquid chromatography with tandem mass spectrometry (HPLC-MS/MS). The following measures at birth were considered: gestational age, birth weight, length as well as head and chest circumference. Results: Pregnancy duration was inversely associated with natural $\log$ concentrations $(\mu \mathrm{g} / \mathrm{g}$ creatinine) of MEP (standardized regression coefficient $(\beta)=-0.2, \mathrm{p}=0.04$ ) after adjustment for a variety of confounders. Significant impact of MOiNP on head circumference $(\beta=-0.1, p=0.05)$ was also observed. Conclusions: The study findings add further support to the hypothesis that phthalate exposure may be associated with shorter pregnancy duration and a decreased head circumference, and underscore importance of public health interventions to reduce that exposure.
\end{abstract}

Key words:

Prenatal exposure, Gestational age, Cohort study, Phthalates, Urinary metabolites, Birth outcomes

\section{INTRODUCTION}

Phthalates are frequently used as plasticizers and solvents, and thus they are widely present in the environment. Low-molecular weight phthalates (low-MWP) such as diethyl phthalate (DEP) are mostly metabolized to their hydrolytic monoesters. They are used as coating for pharmaceuticals or in personal care products, including cosmetics or perfumes [1]. High-molecular weight phthalates (high-MWP), with $\geq 8$ carbons in the alkyl chain (e.g., di(2-ethylhexyl) phthalate (DEHP)), are metabolized to their hydrolytic monoesters, which are extensively transformed to oxidative products. High-molecular weight phthalates are present in polyvinylchloride floors, wall coverings, food packaging and medical devices [1].

Fetal exposure to phthalates is of particular importance because their metabolites can cross placenta and have

The study was performed under the project No. DEC-2011/01/B/ NZ7/06462 "Phthalate exposure and birth outcome and child neurodevelopment" from the National Science Centre, Poland. Project manager: Kinga Polańska, Ph.D.

Received: May 22, 2015. Accepted: October 20, 2015.

Corresponding author: K. Polańska, Nofer Institute of Occupational Medicine, Department of Environmental Epidemiology, św. Teresy 8, 91-348 Łódź, Poland (e-mail: kinga@imp.lodz.pl). 
been found in amniotic fluid, placental tissue, cord blood and neonatal meconium [2-6]. During prenatal period there is a critical window for organ and system development when exposure to chemicals, at the level that is not dangerous for adults, may adversely affect morphology and functioning of the systems. Birth outcomes, such as birth weight, have been frequently used for evaluation of fetal development and have been indicated to predict occurrence of diseases and neurodevelopment delay later in life [7-9].

Several studies on the effects of prenatal phthalate exposure on pregnancy duration and birth outcomes have been published [4-6,10-17]. However, the studies evaluating the impact of phthalate exposure on duration of pregnancy are not consistent. Some of them have indicated no effect [10] and other a decreased [4,6,14-17] as well as increased gestational age $[11,13]$. In addition, in some studies $[10,12]$ no association between phthalate exposure and birth outcomes has been observed, whereas in other statistically significant positive [11] and negative associations have been reported $[5,6]$.

The aim of this study was to assess the impact of prenatal phthalate exposure on pregnancy duration and various birth outcomes.

\section{MATERIAL AND METHODS}

\section{Study design and population}

The present study is based on the data from the Polish Mother and Child Cohort (REPRO_PL) - a multicenter prospective cohort study launched in 2007 with the aim to evaluate a variety of environmental factors contributing to the pregnancy outcomes, children's health and neurodevelopment. The mothers' recruitment and follow-up procedures have been previously published [18]. The women were recruited provided they fulfilled the following inclusion criteria: single pregnancy up to 12 weeks of gestation, no assisted conception, no pregnancy complications, and no chronic diseases as specified in the study protocol. While the whole REPRO_PL cohort consists of 1700 mother-child pairs, due to organizational and financial restrictions, the current analysis focused only on 165 randomly selected pregnant women and their newborns from Łódź district.

The study was approved by the Bioethical Committee of the Nofer Institute of Occupational Medicine (NIOM), Łódź, Poland, and a written consent was obtained from all the mothers before commencement of the study.

\section{Measurements of urinary phthalate metabolites Sample collection and selection of phthalate metabolites for exposure assessment}

Prenatal exposure to the following phthalates: diethyl phthalate (DEP), di-iso-butyl phthalate (DiBP), di-nbutyl phthalate (DnBP), butyl-benzyl phthalate (BBzP), di(2-ethylhexyl) phthalate (DEHP), di-iso-nonyl phthalate (DiNP) and di-n-octyl phthalate (DOP) was determined by measuring phthalate metabolites in the spot urine collected from the mothers between the 3034th week of pregnancy. The third trimester of pregnancy was selected for exposure assessment as in this period fetal growth velocity is the highest, so for pregnancy outcomes it has been implicated as having the most relevance. The spot urine samples were collected into polyethylene cups and stored at $-20^{\circ} \mathrm{C}$ until analysis, which was performed at NIOM.

The following 11 phthalate metabolites were measured: mono-ethyl phthalate (MEP), mono-iso-butyl phthalate (MiBP), mono-n-butyl phthalate (MnBP), 3OH-mono-n-butyl phthalate (OH-MnBP), mono-benzyl phthalate (MBzP), mono-(2-ethylhexyl) phthalate (MEHP), mono-(2-ethyl-5-hydroxyhexyl) phthalate (MEHHP), mono-(2-ethyl-5-oxohexyl) phthalate (MEOHP), monohydroxy-iso-nonyl phthalate (MHiNP), mono-oxo-isononyl phthalate (MOiNP), and mono-n-octyl phthalate (MOP). Molar concentrations of MnBP and OH-MnBP were summarized as total DnBP; MEHP, MEHHP 
and MEOHP as total DEHP and MHiNP and MOiNP as DiNP.

In addition, high-MWP (as the sum of molar concentrations of MEHP, MEHHP, MEOHP, MHiNP, MOiNP and MOP) and low-MWP (as the sum of molar concentrations of MEP, MiBP, MnBP, OH-MnBP and MBzP) were calculated. The selected phthalate metabolites were similar as in other studies and indicated the proxy of exposure to different types of products [1,12,19-22].

\section{Analytical protocol}

The details regarding chemical analysis have been previously published [23]. Briefly, urinary phthalate metabolites were determined using the liquid chromatography coupled with tandem mass spectrometry with negative electrospray ionisation (Waters QuattroMicro API tandem mass spectrometer, Waters, USA), in a concentration range of $0.4-500 \mu \mathrm{g} / \mathrm{l}$.

Analytical standards: MEP, MEHP, MEHHP, MEOHP, MnBP, MBzP, MOP, MiBP and their respective ${ }^{13} \mathrm{C}_{4}$-labelled analogues (Cambridge Isotopes Laboratory, UK), as well as MHiNP, MOiNP, OH-MnBP and respective deuterium-labelled internal standards were prepared in $10 \%$ acetonitrile.

Before the chemical analysis, all the samples were spiked with a mixture of internal standards, deconjugated using enzymatic hydrolysis with $\beta$-Glucuronidase - Escherichia coli $\mathrm{K} 12(\mathrm{pH}=6.5)$ and purified by Solid Phase Extraction (SPE) on ISOLUTE C18 96-well Plate (Biotage, Sweden).

Chromatographic separation was performed on a $2.5 \mu \mathrm{m} 3 \times 100 \mathrm{~mm}$ XSelect CSH Phenyl-Hexyl column (Waters, USA) at a flow rate of $0.25 \mathrm{ml} / \mathrm{min}$. The MS (mass spectrometry) parameters were optimized for all the analytes for 2 MRMs (Multi Reaction Monitoring). Limit of detection (LOD) was $0.1 \mu \mathrm{g} / 1$ for MEP, MnBP, OH-MnBP, MEHHP, MEOHP, MHiNP and $0.03 \mu \mathrm{g} / \mathrm{l}$ for MiBP, MBzP, MEHP, MOiNP, MOP.
Creatinine concentration was measured using the Jaffe static method (working range: $0.05-5.00 \mathrm{~g}$ creatinine/l).

\section{Outcome assessment and possible confounders}

The analysis included the following birth outcomes (measured by a clinical nurse after birth with the standard measurement procedures): child birth weight (in grams), birth length, head and chest circumference (in centimeters). Pregnancy duration was estimated using the date of the last menstrual period (LMP) or ultrasound if it differed from the LMP-based estimate by $>2$ weeks.

The mothers completed a detailed questionnaire concerning socio-demographic characteristics, environmental exposures and lifestyle variables 3 times during pregnancy (weeks: 8-12, 20-24 and 30-34). The questionnaires were administered during personal interviews by trained midwives.

Factors that could confound the relationship between phthalate exposure and birth outcomes were selected a priori from a set of characteristics and then tested (for their association with birth outcomes and with the level of metabolites). The following potential confounders were considered: gestational age (for birth parameters), child gender, maternal active and passive smoking (by the cotinine level in saliva), alcohol consumption during pregnancy, maternal age, height, pre-pregnancy body mass index (BMI), maternal marital, educational and employment status, and parity. Prenatal exposure to tobacco constituents was assessed based on the cotinine level in saliva (collected from the women during the third trimester of pregnancy) at NIOM using the high performance liquid chromatography coupled with tandem mass spectrometry/ positive electrospray ionization (LC-ESI+MS/MS) and isotope dilution method [24].

\section{Statistical analysis}

Continuous data were expressed as mean \pm standard deviation $(\mathrm{M} \pm \mathrm{SD})$ (for birth outcomes, gestational age, 
maternal age, pre-pregnancy BMI and saliva cotinine level, included as continuous variables in the model), and as 50th and 95th percentiles and ranges (for phthalate metabolites). Categorical data were presented as numbers and frequencies (\%). Concentrations of phthalate metabolites below LOD were assigned a value equal to 1/2 LOD (except for MBzP, for which only the detected values were included in the analysis). Phthalate metabolite, creatinine and cotinine levels were log transformed. Of 165 eligible urine samples from the mothers, the creatinine assessment was not performed for 5 samples, and for 10 samples the creatinine level was below the selected value $(0.2 \mathrm{~g} / 1$ and $3.0 \mathrm{~g} / \mathrm{l}$ ) so the final model included 150 samples. Robust linear regression was performed for each phthalate metabolite and for the sum of metabolites. The following 2 sets of confounders were taken into account:

- Model 1 - child gender and gestational age (for biometric parameters at birth),

- Model 2 - all potential confounders significant at 0.1 level in the regression analysis and the creatinine level.

Statistical reasoning was conducted based on the statistical tests with a significance level of 0.05 .

In the multiple-regression analysis, data were expressed as regression coefficient $(\beta)$, its standard error (SE) and $\mathrm{p}$ values. The statistical analyses were performed using R 3.0.1 statistical package.

\section{RESULTS}

\section{Child and parental characteristics}

Demographic, socio-economic, lifestyle and exposure characteristics of the mothers and their children are summarized in Table 1. About $56 \%$ of the children were girls. On average, the children were born at the 39th week of gestation ( \pm 1.5 week) with the mean birth weight of $3308 \mathrm{~g}$ $( \pm 470 \mathrm{~g})$ and length of $55 \mathrm{~cm}( \pm 2.7 \mathrm{~cm})$. The mean maternal age was 31 years $( \pm 4.2$ year). Most of the mothers $(56 \%)$ had a university degree. High proportion of the women were married and employed (> 75\%).

Based on the women's subjective perception of sufficiency of financial resources, about $82 \%$ of the mothers were in a medium socio-economic status category (sufficient money for current expenses with or without possibility to put aside some amount of money) and $13 \%$ indicated a low socio-economic status (insufficient money for current expenses and living). In the case of $46 \%$ of the women, current pregnancy was the first one. Nine percent of the women were categorized as underweight and $17 \%$ of them as overweight or obese, based on prepregnancy BMI. About $5 \%$ of the women consumed alcohol and $13 \%$ of them smoked cigarettes during pregnancy.

\section{Characteristics of the exposure variables}

Table 2 shows the urinary concentrations (uncorrected and creatinine-corrected) of all the measured phthalate

Table 1. Characteristics of the pregnant women, pregnancies and newborns

\begin{tabular}{|c|c|}
\hline Variable & Respondents \\
\hline \multicolumn{2}{|l|}{ Quantitative variables $(\mathrm{M} \pm \mathrm{SD})$} \\
\hline gestational age [weeks] $(\mathrm{N}=165)$ & $39.1 \pm 1.5$ \\
\hline birth weight $[\mathrm{g}](\mathrm{N}=165)$ & $3308.0 \pm 470.0$ \\
\hline length $[\mathrm{cm}](\mathrm{N}=162)^{\mathrm{a}}$ & $54.9 \pm 2.7$ \\
\hline head circumference $[\mathrm{cm}](\mathrm{N}=161)^{\mathrm{a}}$ & $34.0 \pm 1.5$ \\
\hline chest circumference $[\mathrm{cm}](\mathrm{N}=160)^{\mathrm{a}}$ & $33.3 \pm 1.8$ \\
\hline maternal age [years] $(\mathrm{N}=165)$ & $31.4 \pm 4.2$ \\
\hline
\end{tabular}


Table 1. Characteristics of the pregnant women, pregnancies and newborns - cont.

\begin{tabular}{|c|c|}
\hline Variable & Respondents \\
\hline \multicolumn{2}{|l|}{ Qualitative variables [n (\%)] } \\
\hline \multicolumn{2}{|l|}{ gender $(\mathrm{N}=165)$} \\
\hline boys & $72(43.6)$ \\
\hline girls & $93(56.4)$ \\
\hline \multicolumn{2}{|l|}{ parity $(\mathrm{N}=165)$} \\
\hline 0 & $76(46.1)$ \\
\hline$\geq 1$ & $89(53.9)$ \\
\hline \multicolumn{2}{|l|}{ maternal education $(\mathrm{N}=150)^{\mathrm{a}}$} \\
\hline primary/vocational & $15(9.5)$ \\
\hline secondary & $55(34.8)$ \\
\hline higher & $88(55.7)$ \\
\hline \multicolumn{2}{|l|}{ marital status $(\mathrm{N}=165)$} \\
\hline married & $125(76.0)$ \\
\hline unmarried & $40(24.0)$ \\
\hline \multicolumn{2}{|l|}{ maternal employment $(\mathrm{N}=150)^{\mathrm{a}}$} \\
\hline employed & $113(75.8)$ \\
\hline unemployed & $37(24.7)$ \\
\hline \multicolumn{2}{|l|}{ socio-economic status $(\mathrm{N}=131)^{\mathrm{a}}$} \\
\hline high & $7(5.3)$ \\
\hline medium & $107(81.7)$ \\
\hline low & $17(13.0)$ \\
\hline \multicolumn{2}{|l|}{ maternal pre-pregnancy BMI $\left[\mathrm{kg} / \mathrm{m}^{2}\right](\mathrm{N}=165)$} \\
\hline$<18.5$ & $14(8.5)$ \\
\hline $18.5-24.9$ & $123(74.6)$ \\
\hline $25.0-29.9$ & $22(13.3)$ \\
\hline$\geq 30$ & $6(3.6)$ \\
\hline \multicolumn{2}{|l|}{ alcohol consumption during pregnancy $(\mathrm{N}=162)^{\mathrm{a}}$} \\
\hline no & $154(95.1)$ \\
\hline yes & $8(4.9)$ \\
\hline \multicolumn{2}{|l|}{ saliva cotinine level $(\mathrm{N}=165)$} \\
\hline$\leq 10 \mathrm{ng} / \mathrm{ml}$ & $143(86.7)$ \\
\hline$>10 \mathrm{ng} / \mathrm{ml}$ & $22(13.3)$ \\
\hline
\end{tabular}

$\mathrm{M}$ - mean; SD - standard deviation; $\mathrm{N}$ - number of respondents; BMI - body mass index.

${ }^{a}$ For these variables, some data were missing. 
Table 2. Urinary concentrations (uncorrected: $\mathrm{N}=165$ and creatinine-corrected: $\mathrm{N}=150$ ) of phthalate metabolites

\begin{tabular}{|c|c|c|c|c|c|}
\hline Phthalate & Phthalate metabolite & $\begin{array}{c}\text { Samples above } \\
\text { LOD } \\
{[\%]}\end{array}$ & $\mathrm{Me}$ & P95 & $\begin{array}{c}\text { Range } \\
\text { (min.-max) }\end{array}$ \\
\hline \multirow[t]{2}{*}{ DEP } & $\operatorname{MEP}[\mu \mathrm{g} / 1]$ & 100 & 18.7 & 336.4 & $1.5-2922$ \\
\hline & MEP [ $\mu \mathrm{g} / \mathrm{g}$ creatinine] & & 22.7 & 394.7 & $1.7-4235$ \\
\hline \multirow[t]{2}{*}{ DiBP } & $\operatorname{MiBP}[\mu \mathrm{g} / 1]$ & 86 & 10.3 & 359.1 & $<$ LOD-812 \\
\hline & $\mathrm{MiBP}[\mu \mathrm{g} / \mathrm{g}$ creatinine $]$ & & 11.1 & 563.2 & $<$ LOD-1 239 \\
\hline \multirow[t]{4}{*}{ DnBP } & $\operatorname{MnBP}[\mu \mathrm{g} / 1]$ & 95 & 3.6 & 129.5 & < LOD-1 692 \\
\hline & $\mathrm{MnBP}[\mu \mathrm{g} / \mathrm{g}$ creatinine $]$ & & 4.6 & 73.8 & $<$ LOD-846 \\
\hline & $\mathrm{OH}-\mathrm{MnBP}[\mu \mathrm{g} / \mathrm{l}]$ & 96 & 4.0 & 25.2 & $<$ LOD-63 \\
\hline & $\mathrm{OH}-\mathrm{MnBP}[\mu \mathrm{g} / \mathrm{g}$ creatinine $]$ & & 5.0 & 34.7 & < LOD-138 \\
\hline \multirow[t]{2}{*}{ BBzP* } & $\mathrm{MBz} P[\mu \mathrm{g} / 1]$ & 49 & 0.2 & 0.5 & $<$ LOD-8.8 \\
\hline & $\mathrm{MBz} P[\mu \mathrm{g} / \mathrm{g}$ creatinine $]$ & & 0.2 & 0.5 & $<$ LOD-6.7 \\
\hline \multirow[t]{6}{*}{ DEHP } & MEHP $[\mu \mathrm{g} / 1]$ & 66 & 0.2 & 1.3 & $<\mathrm{LOD}-3.5$ \\
\hline & MEHP $[\mu \mathrm{g} / \mathrm{g}$ creatinine] & & 0.2 & 1.6 & $<$ LOD -4.3 \\
\hline & MEHHP [ $\mu \mathrm{g} / 1]$ & 70 & 2.0 & 75.1 & $<$ LOD-256 \\
\hline & MEHHP [ $\mu \mathrm{g} / \mathrm{g}$ creatinine] & & 2.7 & 97.0 & $<$ LOD-431 \\
\hline & MEOHP $[\mu \mathrm{g} / 1]$ & 92 & 1.3 & 55.4 & $<$ LOD-132 \\
\hline & MEOHP $[\mu \mathrm{g} / \mathrm{g}$ creatinine] & & 1.6 & 72.6 & $<$ LOD-140 \\
\hline \multirow[t]{4}{*}{ DiNP } & MHiNP $[\mu \mathrm{g} / 1]$ & 90 & 0.8 & 21.3 & $<$ LOD-98.6 \\
\hline & MHiNP $[\mu \mathrm{g} / \mathrm{g}$ creatinine] & & 1.1 & 20.3 & $<$ LOD-112 \\
\hline & MOiNP [ $\mu \mathrm{g} / 1]$ & 62 & 0.5 & 1.1 & $<$ LOD-3.6 \\
\hline & MOiNP [ $\mu \mathrm{g} / \mathrm{g}$ creatinine] & & 0.4 & 1.7 & $<$ LOD-4.2 \\
\hline \multirow[t]{2}{*}{ DOP } & $\mathrm{MOP}[\mu \mathrm{g} / 1]$ & 63 & 0.2 & 1.3 & $<$ LOD-11.2 \\
\hline & MOP $[\mu g / g$ creatinine $]$ & & 0.2 & 1.3 & $<$ LOD-12.3 \\
\hline DnBP & $\sum \mathrm{MnBP}$ and $3 \mathrm{OH}-\mathrm{MnBP}[\mu \mathrm{mol} / \mathrm{l}]$ & & 0.04 & 0.6 & $<$ LOD-7.7 \\
\hline DEHP & $\sum$ MEHP, MEHHP and MEOHP $[\mu \mathrm{mol} / 1]$ & & 0.02 & 0.3 & $<$ LOD-0.9 \\
\hline DiNP & $\sum$ MHiNP and MHiNP $[\mu \mathrm{mol} / 1]$ & & 0.004 & 0.07 & $<$ LOD-0.3 \\
\hline
\end{tabular}

$\mathrm{N}$ - number of respondents; DEP - diethyl phthalate; DiBP - di-iso-butyl phthalate; DnBP - di-n-butyl phthalate; BBzP - butyl-benzyl phthalate; DEHP - di(2-ethylhexyl) phthalate; DiNP - di-iso-nonyl phthalate; DOP - di-n-octyl phthalate.

* As $49 \%$ of the samples were above LOD (limit of detection) the median was calculated for detected samples.

MEP - mono-ethyl phthalate; MiBP - mono-iso-butyl phthalate; MnBP - mono-n-butyl phthalate; OH-MnBP - 3OH-mono-n-butyl phthalate; MBzP - mono-benzyl phthalate; MEHP - mono-(2-ethylhexyl) phthalate; MEHHP - mono-(2-ethyl-5-hydroxyhexyl) phthalate; MEOHP - mono(2-ethyl-5-oxohexyl) phthalate; MHiNP - mono-hydroxy-iso-nonyl phthalate; MOiNP - mono-oxo-iso-nonyl phthalate; MOP - mono-n-octyl phthalate. $\mathrm{Me}$ - median; P95 - 95th percentile; min. - minimal value; max - maximal value. 
metabolites. We detected 5 out of 11 phthalate metabolites (namely MEP, MnBP, OH-MnBP, MEOHP, and MHiNP) in at least $90 \%$ of the samples. Phthalate BBzP metabolite was detected at the level above LOD in $49 \%$ of the urine samples. The phthalate metabolites with the highest median concentration were: MEP $(18.7 \mu \mathrm{g} / 1,22.7 \mu \mathrm{g} / \mathrm{g}$ creatinine) followed by MiBP $(10.3 \mu \mathrm{g} / 1,11.1 \mu \mathrm{g} / \mathrm{g}$ creatinine $)$ and $\mathrm{OH}-\mathrm{MnBP}(4 \mu \mathrm{g} / \mathrm{l}, 5 \mu \mathrm{g} / \mathrm{g}$ creatinine $)$.

The levels of majority of the analytes were positively correlated within the same urine samples. Except for correlations between MEP and MBzP or DiNP or MOP, and between DiNP and MiBP or DEHP or MOP, all the other phthalates were significantly correlated with each other (with correlation coefficients ranging from $\mathrm{r}=0.2$, $\mathrm{p}<0.05$ to $\mathrm{r}=0.7, \mathrm{p}<0.01$ ) (details included in a previous publication [23]).

\section{Impact of prenatal phthalate exposure}

\section{on pregnancy duration and birth outcomes}

Table 3 presents the effects of prenatal phthalate exposure (based on phthalate metabolites or the molar sum of metabolites) on pregnancy duration and birth outcomes. Based on the model adjusted for child gender, the adverse effect of MEP exposure on pregnancy duration was of borderline significance $(\beta=-0.2, p=0.06)$. Other phthalates were not significantly associated with gestational age. In the analysis adjusted for child gender and gestational age, child length was positively associated with a natural log increase in MHiNP and molar sum of MHiNP and MOiNP ( $\beta=0.3, p=0.02$ for both of the associations). For other phthalates there were no statistically significant associations with any other pregnancy outcomes.

The further adjustment for additional confounders (creatinine, maternal education, marital status, parity, prepregnancy BMI, cotinine level in saliva) indicated a significant impact of MEP on pregnancy duration $(\beta=-0.2$, $p=0.04)$ and MOiNP on head circumference $(\beta=-0.1$, $p=0.05$ ) (Table 4). Other phthalates (as metabolites or the sum of metabolites) were not associated with any other birth outcomes after adjustment.

\section{DISCUSSION}

Our study indicates an inverse association between prenatal exposure to DEP and pregnancy duration after adjustment for a variety of possible confounders. In addition, child head circumference was inversely associated with natural log increase in MOiNP. Associations between prenatal exposure to phthalates and other analyzed birth outcomes were not significant in the multivariable adjusted model.

\section{Exposure assessment}

The urinary concentrations of phthalate metabolites ranged from below LOD to even several 1000-fold higher, which indicates large differences in individual exposure. Overall, exposure levels were well below the health-based guidance values for DEHP (as the sum of MEHHP and MEOHP: $300 \mu \mathrm{g} / \mathrm{l}$ for women of childbearing age) [25]. In our study 95 percentiles for MnBP, MiBP, MEHHP, MEOHP for pregnant women were about twice as high as the reference value specified by the German Human Biomonitoring Commission for adult population [26]. In the case of $\mathrm{MBzP}$ and MOiNP, in our study such values were lower and in the case of MHiNP they were on the same level.

Levels of most of the phthalate metabolites detected in the urine of pregnant women in Poland were in an order of magnitude similar to that observed among pregnant women in Denmark [27]. It is important to note that MEP levels were much lower in Poland (as well as in Denmark and Japan) compared to those observed in Spain, France, the Netherlands and US [10-12,27-29]. In addition, $\mathrm{MBz}$ P was detected only in $49 \%$ of Polish samples, which is similar to the results observed in Denmark (MBzP > LOD in $69 \%$ of the samples) but lower 


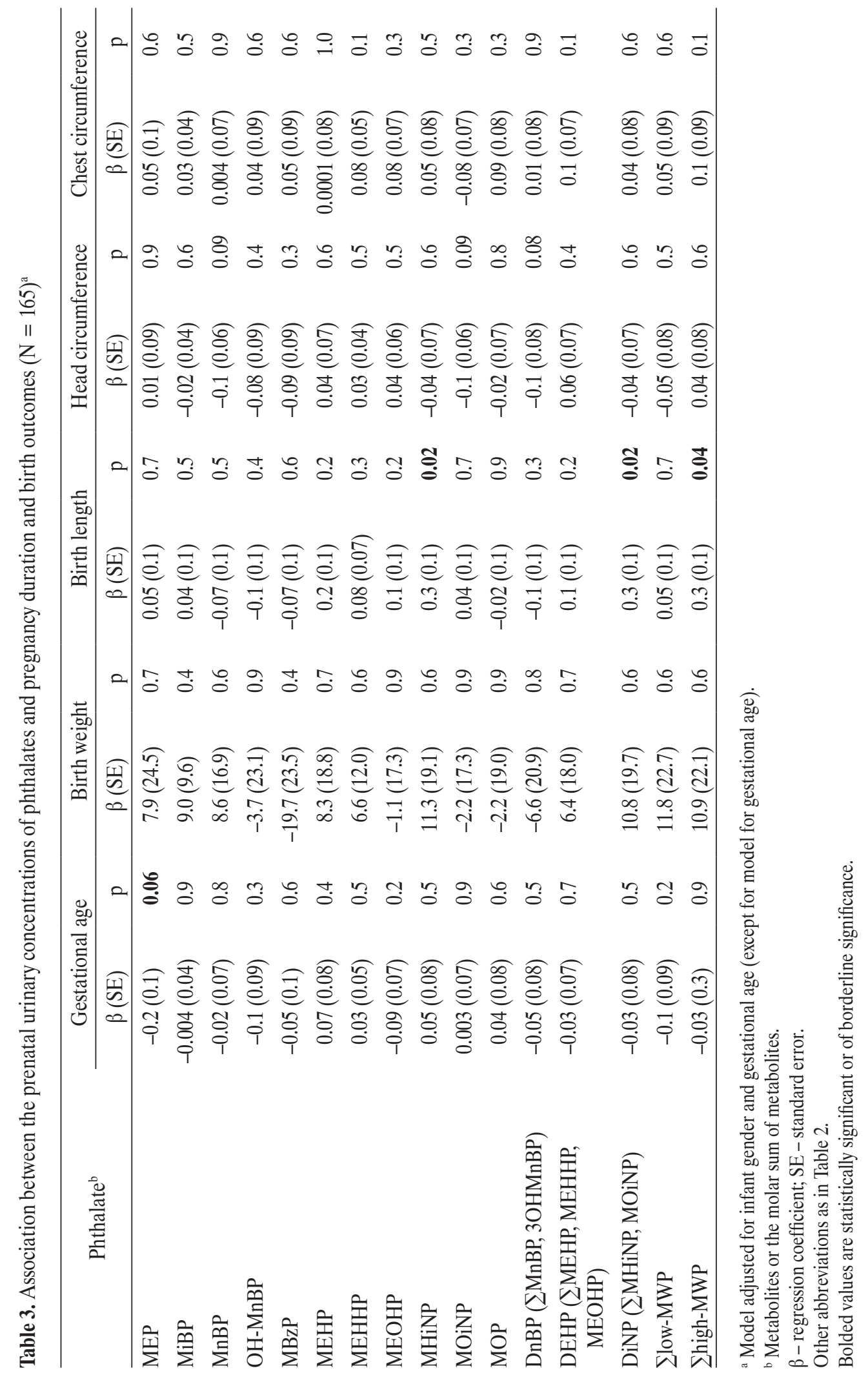




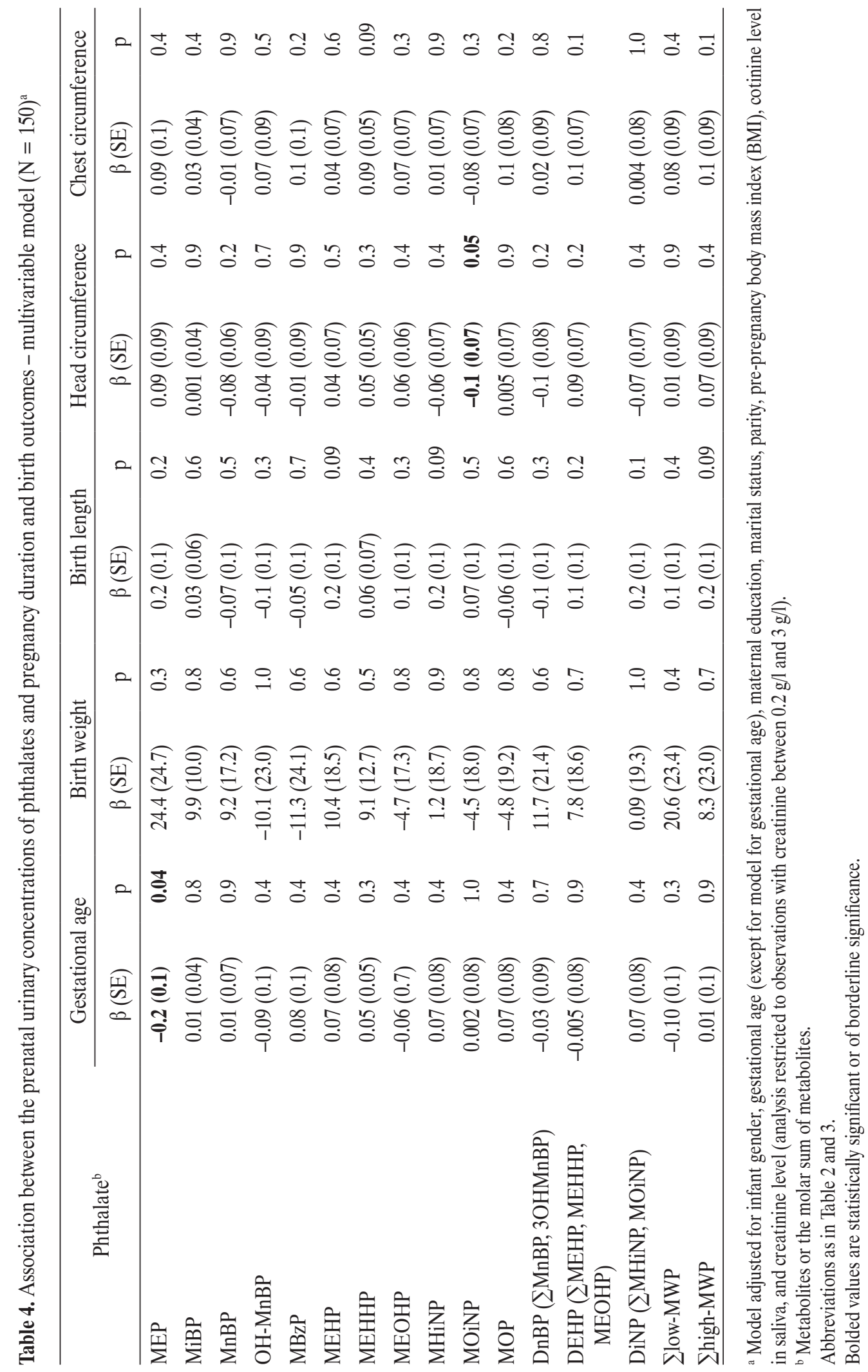


than in the other mentioned studies (where $\mathrm{MBz} P$ was detected in 100\% of the samples) [10-12,27-29].

The differences in the levels of phthalate metabolites between the populations may result from different exposure profiles. The existing studies provide the evidence that urinary biomarkers represent phthalate exposure from various products $[1,21,30]$. The analysis performed by Buckey et al. (2013) indicated a higher level of mono-butyl phthalate (MBP) among pregnant women who used nail polish, MBzP among those who used eye makeup or used makeup on a regular basis, and DEHP metabolites among those who used cologne or perfume [21]. House products (household chemicals or cleaning products, fabric softeners, air fresheners), home flooring or paneling were also associated with urinary phthalates [21]. In addition, food is thought to be a significant source of exposure due to the use of phthalates in packaging [31].

\section{Phthalate exposure and pregnancy duration and birth outcomes}

Taking into account the fact that phthalates are ubiquitous in daily life, potential consequences of human exposure to phthalates have raised concerns in general population and have been studied in susceptible groups, including pregnant women [32]. Results of the studies of the impact of phthalates on pregnancy duration are not consistent. In the studies that measured phthalate metabolite levels in cord blood or, similarly as in our study, in the urine collected in the third trimester of pregnancy, 4 noted significant associations with shortened pregnancy duration or increased odds of preterm birth [4,6,16,17], while 2 other studies indicated longer gestation with an increase in concentrations of phthalate metabolites (which as suggested by Wolff et al. (2009) can result from residual confounding) [11,13]. No association was noted by Suzuki et al. (2010) [10].

Two recently published papers that evaluated the impact of phthalates measured in urine collected 4 times during pregnancy on the risk of preterm birth, indicated that exposure to MEHP, mono-(2-ethyl-5-carboxypentyl) phthalate (MECPP), $\mathrm{DEHP}$ was associated with significantly elevated odds of prematurity, and that exposure to MEHP, MECPP, ¿DEHP, MBP, MEOHP, mono-(2-carboxypropyl) phthalate (MCPP) increased the risk of spontaneous preterm births $[14,15]$. Detailed analyses have shown that the observed associations were strongest for the phthalate levels in urine collected at the beginning of the third trimester of pregnancy [14]. Similarly as in our study, in the study by Huang et al. (2014) [6] MEP exposure was associated with gestational age reduction.

Just as in our analysis, in the study performed by Huang et al. (2014) phthalate exposure decreased the head circumference (statistically significant association has been noted in females) [6]. On the other hand, a positive association between phthalate exposure and the head circumference was observed by Wolff et al. (2008) [11]. In the studies by Suzuki et al. (2010) and Philippat et al. (2012) after adjustment for a variety of confounders, no statistically significant associations were observed between phthalate exposure and birth outcomes $[10,12]$.

In animal studies, phthalates induced a variety of adverse effects, among which most were related to reproductive and developmental outcomes. Phthalates are considered to be endocrine disrupting chemicals in many aspects, including estrogenic, anti-androgenic and anti-thyroid activities [19,33,34]. Pregnant rats exposed to phthalates had reductions in ovarian and uterine weight, progesterone levels and ovulatory follicles. Prenatal phthalate exposure has been reported to result in the increase of developmental abnormalities such as cleft palate and skeletal malformations, increased fetal death and decreased fetal body weight and pregnancy duration [34]. While the majority of animal studies on DEP do not show reproductive and developmental toxicity [34,35], some of the human studies have found significant adverse associations [6]. 
It is crucial to be aware that phthalates in animal studies were usually tested one at a time, while humans are exposed to multiple phthalates simultaneously [35]. Rodent data suggest that exposure to multiple phthalates at low doses conveys risk in a dose additive manner [36-38]. Another point which needs to be considered is that human exposure to DEP occurs primarily via the skin and secondarily via inhalation. In contrast, in almost all animal studies, exposure is oral.

As indicated by Ferguson et al. (2014), different mechanisms can explain the relationship between phthalate exposure and a shortened pregnancy or preterm delivery $[14,15]$. First, phthalate exposure can cause impaired placentation early in pregnancy via induction of oxidative stress [39-41]. Increases in circulating maternal levels of reactive oxygen species can cause apoptosis and alter cytotrophoblast turnover rate in the developing placenta, leading to impaired placentation and in consequence preeclampsia or intrauterine growth restriction (IUGR), which are characteristics of a placental preterm birth $[14,15]$. Second, phthalates have been shown to induce proinflammatory cytokine release in cell lines and have been linked to the increased systemic levels of inflammatory markers [42-44]. Alternative pathways, for example via phthalate disruption of reproductive hormones are plausible as well $[14,15]$.

\section{Confounding factors}

We assessed potential for confounding for a wide range of data on socio-economic factors and lifestyle habits. The advantage of the current analysis is the fact that child prenatal exposure to tobacco constituents was assessed not only based on questionnaire data (performed in majority of the studies) but also on the cotinine level in biological samples, which enabled a more reliable assessment of such an exposure. In our study, we focused on healthy women with no chronic diseases and pregnancy complications. Therefore, such conditions should not alter the associations.

\section{Strengths and limitations}

The prospective study design with well-assessed exposure levels based on biomarker measurements is an advantage of the current analysis. Additionally, a series of detailed questionnaires makes it possible to perform a reliable assessment of exposure and confounding variables. We measured 11 phthalate metabolites, which allows a more comprehensive assessment of exposure.

Some limitations of our study also need to be mentioned. First, the current analysis is based on a relatively small sample size, which might not be large enough to have a statistical power to detect the effect of prenatal phthalate exposure on birth outcomes. Taking into account the sample size of our population, we were not able to assess genderspecific effect indicated in other analyses. Second, our maternal exposure may be too low to elicit the inverse effects reported in other studies. In addition, the exact time of the day and time-void for urine sampling was unavailable. However, it can be assumed that in our population most samples represent first morning voids.

Because most of primary phthalate metabolites have a short half-life and some exposures are unlikely to occur within 8-10 h prior to morning voids, phthalate exposure may be underestimated in some of the samples. Since for DEHP it was possible to analyze primary metabolite (MEHP - the first step of DEHP metabolism pathway) and 2 secondary metabolites representing further steps of its metabolism (i.e., hydroxyl and oxo MEHP - the 2nd and the 3rd step), it was possible to identify the extent (progress) of DEHP metabolism. Thus, we calculated the ratio of the 2 nd to the 1 st step as 59.8 and the 3rd to the 2nd step as 5.7, which are much higher values than those calculated by Enke et al. (2013) (2.4 and 0.9, respectively) [30].

The explanation of this observation is that the time period between exposure to phthalates and urine sampling for the analysis was longer in our study than in the study by Enke et al. (2013) [30]. Nevertheless, we assessed the total daily intake of DEHP and DEP applying calculation 
model of David et al. (2000) [45] and using both primary and secondary metabolites. The total daily intake of DEHP was $108.5 \mu \mathrm{g} /$ day and DEP - $176.5 \mu \mathrm{g} /$ day; which is close to the values calculated based on the same model by Koch et al. (2003) [46].

It needs to be pointed that in majority of the studies in this field, the assessment of exposure was based on phthalate levels in urine collected, as in our study, during the third trimester of pregnancy $[11,13,16,17]$ or in cord blood [4-6]. Additionally, the recently published study by Ferguson et al. (2014) in which phthalate metabolites were measured 4 times in pregnancy period, has indicated that urinary phthalate metabolite levels showed moderate individual and population-wide variability during pregnancy, and that most of them demonstrated a slightly downward sloping trend across gestation [14].

\section{CONCLUSIONS}

The study findings add further support to the hypothesis that phthalate exposure may be associated with a shortened pregnancy duration and a decreased head circumference and they underscore importance of policies and public health interventions to reduce that exposure.

\section{REFERENCES}

1. Koch HM, Calafat AM. Human body burdens of chemicals used in plastic manufacture. Philos Trans R Soc Lond B Biol Sci. 2009;364:2063-78, http://dx.doi.org/10.1098/rstb. 2008.0208.

2. Mose T, Mortensen GK, Hedegaard M, Knudsen LE. Phthalate monoesters in perfusate from a dual placenta perfusion system, the placenta tissue and umbilical cord blood. Reprod Toxicol. 2007;23:83-91, http://dx.doi.org/10.1016/j.reprotox. 2006.08.006.

3. Kato K, Silva MJ, Needham LL, Calafat AM. Quantifying phthalate metabolites in human meconium and semen using automated off-line solid-phase extraction coupled with on-line SPE and isotope-dilution high-performance liquid chromatography-tandem mass spectrometry. Anal Chem. 2006;78:6651-5, http://dx.doi.org/10.1021/ac0608220.

4. Latini G, de Felice C, Presta G, del Vecchio A, Paris I, Ruggieri F, et al. In utero exposure to di-(2-ethylhexyl)phthalate and duration of human pregnancy. Environ Health Perspect. 2003;111:1783-5.

5. Zhang Y, Lin L, Cao Y, Chen B, Zheng L, Ge RS. Phthalate levels and low birth weight: A nested case-control study of Chinese newborns. J Pediatr. 2009;155:500-4, http://dx.doi. org/10.1016/j.jpeds.2009.04.007.

6. Huang Y, Li J, Garcia JM, Lin H, Wang Y, Yan P, et al. Phthalate levels in cord blood are associated with preterm delivery and fetal growth parameters in Chinese women. PLoS One. 2014;9(2):e87430, http://dx.doi.org/10.1371/ journal.pone. 0087430 .

7. Ben-Shlomo Y, Kuh D. A life course approach to chronic disease epidemiology: Conceptual models, empirical challenges and interdisciplinary perspectives. Int $\mathrm{J}$ Epidemiol. 2002;31(2):285-93.

8. Silveira PP, Portella AK, Goldani MZ, Barbieri MA. Developmental origins of health and disease (DOHaD). J Pediatr (Rio J). 2007;83(6):494-504, http://dx.doi.org/10.2223/ JPED.1728.

9. Lau C, Rogers JM. Embryonic and fetal programming of physiological disorders in adulthood. Birth Defects Res C Embryo Today. 2004;72(4):300-12, http://dx.doi.org/ 10.1002/bdrc.20029.

10. Suzuki Y, Niwa M, Yoshinaga J, Mizumoto Y, Serizawa S, Shiraishi H. Prenatal exposure to phthalate esters and PAHs and birth outcomes. Environ Int. 2010;36:699-704, http:// dx.doi.org/10.1016/j.envint.2010.05.003.

11. Wolff MS, Engel SM, Berkowitz GS, Ye X, Silva MJ, Zhu C, et al. Prenatal phenol and phthalate exposures and birth outcomes. Environ Health Perspect. 2008;116:1092-7, http://dx.doi.org/10.1289/ehp.11007.

12. Philippat C, Mortamais M, Chevrier C, Petit C, Calafat AM, Ye X, et al. Exposure to phthalates and phenols during pregnancy and offspring size at birth. Environ 
Health Perspect. 2012;120:464-70, http://dx.doi.org/10.1289/ ehp.1103634.

13. Adibi JJ, Hauser R, Williams PL, Whyatt RM, Calafat AM, Nelson H, et al. Maternal urinary metabolites of di-(2-ethylhexyl) phthalate in relation to the timing of labor in a US multicenter pregnancy cohort study. Am J Epidemiol. 2009;169:1015-24, http://dx.doi. org/10.1093/aje/kwp001.

14. Ferguson KK, McElrath TF, Ko YA, Mukherjee B, Meeker JD. Variability in urinary phthalate metabolite levels across pregnancy and sensitive windows of exposure for the risk of preterm birth. Environ Int. 2014;70:118-24, http://dx.doi.org/10.1016/j.envint.2014.05.016.

15. Ferguson KK, McElrath TF, Meeker JD. Environmental phthalate exposure and preterm birth. JAMA Pediatr. 2014;168(1):61-7, http://dx.doi.org/10.1001/jamapediatrics.2013.3699.

16. Whyatt RM, Adibi JJ, Calafat AM, Camann DE, Rauh V, Bhat HK, et al. Prenatal di(2-ethylhexyl)phthalate exposure and length of gestation among an inner-city cohort. Pediatrics. 2009;124(6):e1213-20, http://dx.doi.org/10.1542/ peds.2009-0325.

17. Meeker JD, Hu H, Cantonwine DE, Lamadrid-Figueroa H, Calafat AM, Ettinger AS, et al. Urinary phthalate metabolites in relation to preterm birth in Mexico city. Environ Health Perspect. 2009;117(10):1587-92, http://dx.doi. org/10.1289/ehp.0800522.

18. Polańska K, Hanke W, Gromadzińska J, Ligocka D, Gulczyńska E, Sobala W, et al. Polish mother and child cohort study - Defining the problem, the aim of the study and methodological assumptions. Int J Occup Med Environ Health. 2009;22:383-91, http://dx.doi.org/10.2478/v10001009-0037-0.

19. Centers for Disease Control and Prevention, Department of Health and Human Services. Fourth national report on human exposure to environmental chemicals [Internet]. Atlanta: The Centers; 2009 [cited 2015 May 19]. Available from: http://www.cdc.gov/exposurereport.
20. Saravanabhavan G, Guay M, Langlois É, Giroux S, Murray J, Haines D. Biomonitoring of phthalate metabolites in the Canadian population through the Canadian Health Measures Survey (2007-2009). Int J Hyg Environ Health.2013;216(6):652-61,http://dx.doi.org/10.1016/j.ijheh. 2012.12.009.

21. Buckley JP, Palmieri RT, Matuszewski JM, Herring AH, Baird DD, Hartmann KE, et al. Consumer product exposures associated with urinary phthalate levels in pregnant women. J Expo Sci Environ Epidemiol. 2012;22:468-75, http://dx.doi.org/10.1038/jes.2012.33.

22. Wittassek M, Koch HM, Angerer J, Brüning T. Assessing exposure to phthalates - The human biomonitoring approach. Mol Nutr Food Res. 2011;55(1):7-31, http://dx.doi. org/10.1002/mnfr.201000121.

23. Polanska K, Ligocka D, Sobala W, Hanke W. Phthalate exposure and child development: The Polish Mother and Child Cohort Study. Early Human Dev. 2014;90:477-85, http:// dx.doi.org/10.1016/j.earlhumdev.2014.06.006.

24. Stragierowicz J, Mikołajewska K, Zawadzka-Stolarz M, Polańska K, Ligocka D. Estimation of cutoff values of cotinine in urine and saliva for pregnant women in Poland. Biomed Res Int. 2013;2013:386784, http://dx.doi. org $/ 10.1155 / 2013 / 386784$.

25. Becker K, Göen T, Seiwert M, Conrad A, Pick-Fuss H, Müller J, et al. GerES IV: Phthalate metabolites and bisphenol A in urine of German children. Int J Hyg Environ Health. 2009;212(6):685-92, http://dx.doi.org/10.1016/j.ijheh. 2009.08.002.

26. Schulz C, Wilhelm M, Heudorf U, Kolossa-Gehring M. Reprint of "Update of the reference and HBM values derived by the German Human Biomonitoring Commission". Int J Hyg Environ Health. 2012;215:150-8, http://dx.doi. org/10.1016/j.ijheh.2012.01.003.

27. Frederiksen H, Jensen TK, Jørgensen N, Kyhl HB, Husby S, Skakkebæk NE, et al. Human urinary excretion of non-persistent environmental chemicals: An overview of Danish data collected between 2006 and 2012. 
Reproduction. 2014;147(4):555-65, http://dx.doi.org/10. 1530/REP-13-0522.

28. Casas L, Fernández MF, Llop S, Guxens M, Ballester F, Olea N, et al. Urinary concentrations of phthalates and phenols in a population of Spanish pregnant women and children. Environ Int. 2011;37(5):858-66, http://dx.doi.org/ 10.1016/j.envint.2011.02.012.

29. Ye X, Pierik FH, Hauser R, Duty S, Angerer J, Park MM, et al. Urinary metabolite concentrations of organophosphorous pesticides, bisphenol $\mathrm{A}$, and phthalates among pregnant women in Rotterdam, the Netherlands: The Generation R study. Environ Res. 2008;108(2):260-7, http://dx.doi.org/10.1016/j.envres.2008.07.014.

30. Enke U, Schleussner E, Pälmke C, Seyfarth L, Koch HM. Phthalate exposure in pregnant women and newborns The urinary metabolite excretion pattern differs distinctly. Int J Hyg Environ Health. 2013;216(6):735-42, http://dx.doi. org/10.1016/j.ijheh.2013.01.006.

31. Schettler T. Human exposure to phthalates via consumer products. Int J Androl. 2006;29(1):134-9, http://dx.doi. org/10.1111/j.1365-2605.2005.00567.x.

32. Jurewicz J, Hanke W. Exposure to phthalates: Reproductive outcome and children health. A review of epidemiological studies. Int J Occup Med Environ Health. 2011;24:115-41, http://dx.doi.org/10.2478/s13382-011-0022-2.

33. Lyche JL, Gutleb AC, Bergman A, Eriksen GS, Murk AJ, Ropstad E, et al. Reproductive and developmental toxicity of phthalates. J Toxicol Environ Health B Crit Rev. 2009; 12(4):225-49, http://dx.doi.org/10.1080/10937400903094091.

34. United States Environmental Protection Agency [Internet]. The Agency [cited 2015 May 19]. Phthalates. TEACH chemical summary (revised 2007). Available from: http://www. google.pl/url? sa $=t \& r c t=j \& q=\&$ esrc $=$ s\&source $=w e b$ $\& c d=1 \& v e d=0$ ahUKEwivp_Su1J7JAhUiAHMKHYE GAK8QFggkMAA\&url=http\%3A\%2F\%2Fnepis.epa. gov\%2FExe\%2FZyPURL.cgi\%3FDockey\%3DP100BNSK. TXT\&usg=AFQjCNGK3FydcJz7zq1NJ-fcn6GVnEYldQ $\&$ bvm $=$ bv. 108194040, d.bGQ \& cad $=$ rja.
35. Swan SH. Environmental phthalate exposure in relation to reproductive outcomes and other health endpoints in humans. Environ Res. 2008;108(2):177-84, http://dx.doi. org/10.1016/j.envres.2008.08.007.

36. Gray LE Jr., Wilson VS, Stoker T, Lambright C, Furr J, Noriega N, et al. Adverse effects of environmental antiandrogens and androgens on reproductive development in mammals. Int J Androl. 2006;29:96-104, http://dx.doi. org/10.1111/j.1365-2605.2005.00636.x.

37. Howdeshell KL, Rider CV, Wilson VS, Hray LE. Mechanisms of action of phthalate esters, individually and in combination, to induce abnormal reproductive development in laboratory rats. Environ Res. 2008;108(2):168-76, http:// dx.doi.org/10.1016/j.envres.2008.08.009.

38. Howdeshell KL, Wilson VS, Furr J, Lambright CR, Rider CV, Blystone CR, et al. A mixture of five phthalate esters inhibits fetal testicular testosterone production in the Sprague Dawley rat in a cumulative, dose additive manner. Toxicol Sci. 2008;105(1):153-65, http://dx.doi.org/10.1093/toxsci/kfn077.

39. Fan J, Traore K, Li W, Amri H, Huang H, Wu C, et al. Molecular mechanisms mediating the effect of mono(2-ethylhexyl) phthalate on hormone-stimulated steroidogenesis in MA-10 mouse tumor Leydig cells. Endocrinology. 2010;151(7):3348-62, http://dx.doi.org/10.1210/en.20 10-0010.

40. Tetz LM, Cheng AA, Korte CS, Giese RW, Wang P, Harris $\mathrm{C}$, et al. Mono-2-ethylhexyl phthalate induces oxidative stress responses in human placental cells in vitro. Toxicol Appl Pharmacol. 2013;268(1):47-54, http://dx.doi. org/10.1016/j.taap.2013.01.020.

41. Ferguson KK, Loch-Caruso R, Meeker JD. Exploration of oxidative stress and inflammatory markers in relation to urinary phthalate metabolites: NHANES 1999-2006. Environ Sci Technol. 2012;46(1):477-85, http://dx.doi.org/10.1021/ es202340b.

42. Ferguson KK, Loch-Caruso R, Meeker JD. Urinary phthalate metabolites in relation to biomarkers of inflammation and oxidative stress: NHANES 1999-2006. Environ 
Res. 2011;111(5):718-26, http://dx.doi.org/10.1016/j.envres. 2011.02.002.

43. Jepsen KF, Abildtrup A, Larsen ST. Monophthalates promote IL- 6 and IL- 8 production in the human epithelial cell line A549. Toxicol In Vitro. 2004;18(3):265-9, http://dx.doi. org/10.1016/j.tiv.2003.09.008.

44. Nishioka J, Iwahara C, Kawasaki M, Yoshizaki F, Nakayama H, Takamori K. Di-(2-ethylhexyl) phthalate induces production of inflammatory molecules in human macrophages.
Inflamm Res. 2012;61(1):69-78, http://dx.doi.org/10.1007/ s00011-011-0390-x.

45. David RM. Exposure to phthalate esters. Environ Health Perspect. 2000;108:A440.

46. Koch HM, Rossbach B, Drexler H, Angerer J. Internal exposure of general population to DEHP and other phthalates Determination of secondary and primary phthalate monoester metabolites in urine. Environ Res. 2003;93:177-85, http://dx.doi.org/10.1016/S0013-9351(03)00083-5.

This work is available in Open Access model and licensed under a Creative Commons Attribution-NonCommercial 3.0 Poland License - http://creativecommons.org/ licenses/by-nc/3.0/pl/deed.en. 